\title{
Thiopurine S-Methyltransferase Phenotype and Genotype in Pediatric Patients with Inflammatory Bowel Disease; Implication for Azathioprine Treatment
}

Maciej Jankowski ${ }^{1,2^{\star}}$, Piotr Landowski ${ }^{3}$, Robert Kowalski ${ }^{1}$, Ewelina Kreft ${ }^{1}$, Irena Audzeyenka ${ }^{2}$, Małgorzata Kasztan $^{1}$, Barbara Kamińska ${ }^{3}$, and Mirosława Szczepańska-Konkel

${ }^{1}$ Department of Therapy Monitoring and Pharmacogenetics, Medical University of Gdańsk, Poland

${ }^{2}$ Laboratory of Cellular and Molecular Nephrology, Mossakowski Medical Research Centre PAS, Warsaw, Poland

${ }^{3}$ Department of Pediatric Gastroenterology, Hepatology and Nutrition, Medical University of Gdańsk, Poland

\begin{abstract}
Inflammatory Bowel Disease (IBD) is more prevalent in children than adults, and the incidence is increasing. IBD is treated with thiopurines, metabolized by thiopurine S-methyltransferase (TPMT) and inter-individual variability in activity of TPMT affecting therapy efficiency and drug toxicity arises from genetic polymorphisms, mainly TPMT*2, ${ }^{*} 3 A$, and ${ }^{*} 3 C$. The aim was to investigate the frequency distribution of TPMT activity, determine the penetration rate of TPMT*2, ${ }^{*} 3 A$, and ${ }^{*} 3 C$ alleles in children, and compare TPMT activity in children and adults with IBD. The study included 85 children, $45 \%$ with Crohn's disease (CD) and 55\% with ulcerative colitis (UC), and 31 adults with IBD. TPMT activity was measured with radiochemistry. TPMT*2, ${ }^{*} 3 A$, and ${ }^{*} 3 C$ alleles were investigated with PCR and restriction fragment length polymorphism analyses. Children showed median TPMT activities of 13.12 and 13.19 $\mathrm{U} / \mathrm{ml} \mathrm{RBC}$ in $\mathrm{CD}$ and $\mathrm{UC}$, respectively, with 4.8 -fold variability (range, $4.74-22.56 \mathrm{U} / \mathrm{ml} \mathrm{RBC}$ ). TPMT activity was similar in children and adults; ranges: $5.56-21.34$ vs. 9.61-17.84 U/ml RBC, respectively, in CD; and 4.74-22.56 vs. 5.19-21.98 U/ml RBC, respectively, in UC. Patients with CD and UC treated with azathioprine displayed similar TPMT activities, similar adverse event frequencies, and similar numbers of non-responders. One out of 85 patients $(1.18 \%)$ was heterozygous with TPMT*1/TPMT*2 (TPMT activity: $5.19 \pm 0.05 \mathrm{U} / \mathrm{ml} \mathrm{RBC}$ ). Individuals with low-intermediate TPMT activity $(<8 \mathrm{U} / \mathrm{ml} \mathrm{RBC})$ did not carry mutant alleles ${ }^{*} 3 A$ or ${ }^{*} 3 \mathrm{C}$. TPMT phenotypes were similar in children and adults with inflammatory bowel disease.
\end{abstract}

Keywords: Azathioprine; Children; Thiopurine S-Methyltransferase; Inflammatory Bowel Disease

Abbreviations: CD: Crohn's Disease; IBD: Inflammatory Bowel Disease; RBC: Red Blood cells; TPMT: Thiopurine S-Methyltransferase; UC: Ulcerative Colitis

\section{Introduction}

Epidemiological studies from Europe have shown an increasing incidence of pediatric inflammatory bowel disease (IBD). Childhoodonset IBD accounts for nearly $30 \%$ of all cases and over $25 \%$ of patients are diagnosed under the age of 16. Furthermore, IBD is more extensive and severe in children and adolescents than in adults $[1,2]$. Purine analogues, like azathioprine, and its active metabolite, 6-mercaptopurine, are considered first-line steroid-sparing immunosuppressive therapies for treating IBDs, including Crohn's disease (CD) and ulcerative colitis (UC). Additionally, thiopurines have demonstrated broad inter-individual variability in terms of response; $15-28 \%$ of patients experienced adverse drug reactions (e.g., bone marrow depression, hepatic and pancreatic dysfunctions) and $9 \%$ of patients were resistant to thiopurines [3,4]. It has been established that adverse clinical conditions mainly result from thiopurine metabolism, involving S-methylation catalyzed by thiopurine S-methyltransferase (TPMT). TPMT is a cytosolic enzyme expressed ubiquitously in humans; e.g., in liver, intestine, kidney, lymphocytes, and red blood cells, RBCs [5]. TPMT expression/activity in the liver, the major body compartment for deactivating thiopurines, was correlated with TMPT activity measured in RBCs [6]. Therefore, in clinical practice, TPMT activity is measured in RBC lysates. The susceptibility of patients to adverse drug reactions is due to inter-individual variations in TPMT activity, a consequence of genetic polymorphisms. TPMT activity varies over a large range, but about $0.3 \%$ of Caucasians exhibit complete deficiency, and $11 \%$ exhibit intermediate TPMT activity. These subjects are at elevated risk of life-threatening thiopurine-induced adverse drug reactions, and they should be considered for alternative forms of therapy, or they should receive low doses of thiopurines [7]. To date, 30 variant alleles $\left(\mathrm{TPMT}^{\star} 2-{ }^{*} 28\right.$ ) have been identified that are predictive of decreased TPMT activity compared to the wild-type allele (TPMT $\left.{ }^{\star} 1\right)$. Importantly, the variant alleles $\mathrm{TPMT}^{\star} 2,{ }^{*} \mathrm{~A}$, and ${ }^{*} \mathrm{C}$ account for over $95 \%$ of inherited TPMT deficiency cases in Caucasian subjects $[8,9]$. This has led to the general assumption that TPMT phenotype/ genotype should be determined in pediatric patients with IBD before treating with thiopurines [10]. The primary objective of the current study was to investigate the TPMT activity frequency distribution and the penetration rates of $\mathrm{TPMT}^{\star} 2,{ }^{*} 3 \mathrm{~A}$, and ${ }^{\star} 3 \mathrm{C}$ alleles in children with CD and UC. The secondary objective was to compare TPMT activities in children and adults. Understanding how these variables occur in pediatric patients with IBD is critical for optimizing the management of IBD in children.

*Corresponding author: Maciej Jankowski, Department of Therapy Monitoring and Pharmacogenetics, Medical University of Gdańsk, Poland, Tel: (+4858) 3492776; Fax: (+4858) 3492784; E-mail: majank@gumed.edu.pl

Received June 1, 2013; Accepted August 17, 2013; Published August 30, 2013

Citation: Jankowski M,Landowski P,Kowalski R,Kreft E,Audzeyenka I, et al., (2013) Thiopurine S-Methyltransferase Phenotype and Genotype in Pediatric Patients with Inflammatory Bowel Disease; Implication for Azathioprine Treatment. J Pharmacovigilance 1: 113. doi:10.4172/2329-6887.1000113

Copyright: ( 2013 Jankowski M, et al., This is an open-access article distributed under the terms of the Creative Commons Attribution License, which permits unrestricted use, distribution, and reproduction in any medium, provided the original author and source are credited. 
Citation: Jankowski M,Landowski P,Kowalski R,Kreft E,Audzeyenka I, et al., (2013) Thiopurine S-Methyltransferase Phenotype and Genotype in Pediatric Patients with Inflammatory Bowel Disease; Implication for Azathioprine Treatment. J Pharmacovigilance 1: 113. doi:10.4172/2329-6887.1000113

Page 2 of 5

\section{Materials and Methods}

\section{Study patients}

The experiments were conducted in accordance with the protocol approved by the Regional Bioethical Commission at the Medical University of Gdansk (NKEBN/2/2009). Patients were included in the study after they or their parents had been fully informed and had signed the study consent form. In addition, verbal assent was obtained from older children. The cutoff age was $\leq 16$ years for children, due to physical development and the completion of puberty. Diagnosis of CD or UC was established by standard clinical, radiological, histological, and endoscopic criteria. One hundred-sixteen patients (85 children and 31 adults) with IBD were included in the study; all were Caucasian. For assessments of CD and UC activities, we used the Crohn's disease activity index (CDAI) and the Truelove-Witts score, respectively.

\section{TPMT phenotyping}

Blood samples were drawn by venipuncture and collected into heparinized vacutainer tubes. After measuring the hematocrit, washed RBC lysates were prepared, as describe elsewhere, and stored at $-80^{\circ} \mathrm{C}$. In this condition, the TPMT enzyme remains stable for several weeks [11]. TPMT activity in RBC lysates was measured with a radiochemical method based on the conversion of 6-mercaptopurine to 6-methylmercaptopurine in the presence of $\left[{ }^{14} \mathrm{C}\right.$-methyl]-Sadenosyl-L-methionine (PerkinElmer, MA, USA), as the methyl donor [6]. Briefly, $50 \mu \mathrm{l}$ of RBC lysate was incubated with $156 \mathrm{mM} \mathrm{K}_{2} \mathrm{HPO}_{4} /$ $\mathrm{KH}_{2} \mathrm{PO}_{4} \mathrm{pH} 7.5$ and $7.5 \mathrm{mM}$ 6-mercaptopurine for $3 \mathrm{~min}$ at $37^{\circ} \mathrm{C}$. The enzyme reaction was initiated by the addition of the following reagents: $12.5 \mu \mathrm{M}\left[{ }^{14} \mathrm{C}\right.$-methyl]-S-adenosyl-L-methionine (specific activity 1.81 $\mathrm{GBq} / \mathrm{mmol}$ ), $12.5 \mu \mathrm{M}$ S-adenosyl-L-methionine, $1 \mathrm{mM}$ dithiothreitol (DTT), and $50 \mu \mathrm{M}$ allopurinol. The reaction tubes were incubated for $1 \mathrm{~h}$ at $37^{\circ} \mathrm{C}$, and then, the reaction was stopped with the addition 0.5 $\mathrm{M}$ borate buffer ( $\mathrm{pH} \mathrm{10)}$. The 6-methylmercaptopurine product was extracted into the organic phase of $20 \%$ isoamyl alcohol in toluene and placed in a scintillation cocktail (Ultima ${ }^{\text {Tw }}$ Gold LSC). Radioactivity was measured in a 1409 Wallec liquid scintillation counter. TPMT activity
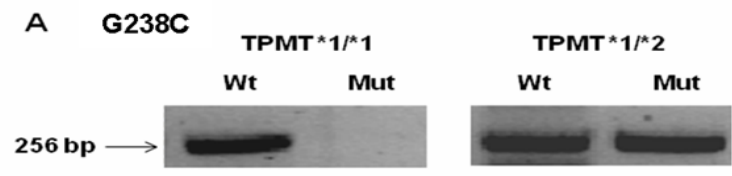

B

C
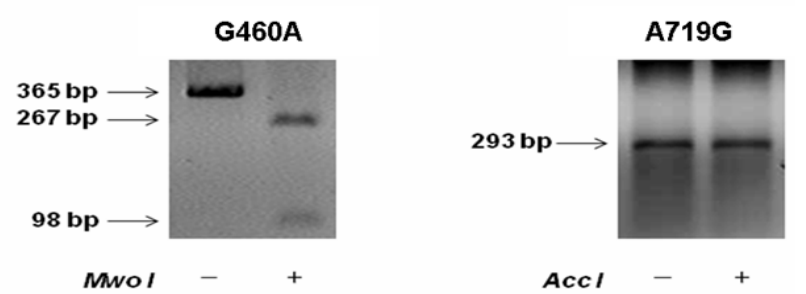

Figure 1: Genotyping scheme: Detection of a wild-type TPMT*1/*1 and heterozygous TPMT*1/*2 using PCR-based methods to detect G238 mutation of TPMT ${ }^{*} 1 / * 2$ (A). Detection of a wild-type TPMT*1/*1 after PCR and Mwo I digestion to detect G460A mutation (B) and after Acc / digestion to detect A719G mutation (C). An ethidium bromide-staining gel is shown. $b p=b a s e$ paris; Mut=mutant; $\mathrm{Wt}=$ wild type. was expressed as the amount of 6-methylmercaptopurine formed

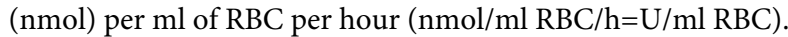

\section{TPMT genotyping}

Total genomic DNA was isolated from whole blood samples with a standard procedure (Blood Mini, Heliconius A \& A Biotechnology). PCR amplification was performed to detect the G238C transversion in the TPMT ${ }^{\star} 2$ allele and the transition mutations, G460A and A719G, in the TPMT ${ }^{*} 3 A$ and $\mathrm{TPMT}^{*} 3 \mathrm{C}$ alleles, respectively [12] To detect the G238C transversion, two pairs of primers were used. The first pair (F1 5'-GTATGATTTTATGCAGGTTTG-3' and R 5 '-TAAATAGGAACCATCGGACA-3') detected the wild type allele, and the second pair (F2 5'-GTATGATTTTATGCAGGTTTC-3' and $\mathrm{R} 5{ }^{\prime}$-TAAATAGGAACCATCGGACA-3') detected the G238C mutation. A DNA fragment was amplified with $\mathrm{F} 1$ and $\mathrm{R}$ primers when G238 (wild-type) was present, whereas a DNA fragment was amplified with F2 and R primers when C238 (mutant) was present (Figure 1A).

PCR was performed in duplicate in a total volume of $50 \mu \mathrm{l}$ containing: $30 \mathrm{ng}$ genomic DNA, $0.5 \mu \mathrm{M}$ of each sense and antisense primer, $0.2 \mathrm{mM}$ dNTPs, $2.5 \mathrm{mM} \mathrm{MgCl}_{2}$, and $1.25 \mathrm{U}$ of GoTaq ${ }^{\circledR}$ Flexi DNA polymerase. The conditions for PCR were as follows: $1 \mathrm{~min}$ denaturation at $94^{\circ} \mathrm{C}, 2 \mathrm{~min}$ annealing at $57^{\circ} \mathrm{C}, 1 \mathrm{~min}$ extension at $72^{\circ} \mathrm{C}$ for 30 cycles, and a final $7 \mathrm{~min}$ extension at $72^{\circ} \mathrm{C}$. The same PCR protocol was used to detect the G460A and A719G transitions with the following primers:

\section{G460A: F: 5 `-ATAACAGAGTGGGGAGGCTGC-3` and}

\section{R: 5 '-CTAGAACCCAGAAAA AGTATAG-3}

\section{A719G: $\quad$ F: $5^{`}$-TGTTGGGATTACAGGTGTGAGCCAC-3} and

\section{R: 5 `-CAGGCTTTAGCATAATTTTCAATTCCTC-3`}

The amplification products were purified on microcolumns (GenElute ${ }^{\text {mm}}$ PCR Clean-Up Kit, Sigma) and digested with the appropriate restriction enzyme (Mwo I or Acc I, New England BioLabs, UK). Mwo I entirely digested the wild-type DNA into two shorter fragments, but no digestion occurred in the presence of a G460A mutation. Conversely, Acc I did not digest wild-type DNA, but the A719G mutation introduced an Acc I restriction site in the sequence. The Mwo I and Acc I digestions were performed with $1 \mu \mathrm{g}$ of product DNA at $60^{\circ} \mathrm{C}$ for $1 \mathrm{~h}$ and at $37^{\circ} \mathrm{C}$ for $1.5 \mathrm{~h}$, respectively. Digested products were separated on a $2.5 \%$ agarose gel, stained with ethidium bromide, and visualized with UV irradiation (Figures 1B and 1C).

\section{Statistical methods}

Statistical analysis was performed with Sigma Plot computer software version 11. The Mann-Whitney $\mathrm{U}$ test was used to compare TPMT enzyme activity between the groups.

\section{Results}

Eighty-five pediatric patients with IBD were included in the study; their characteristics are displayed in Table 1. These patients included $45 \%$ with CD and 55\% with UC; both groups comprised about $58 \%$ males. The median patient ages in the CD and UC groups were 13 and 14 years, respectively, with similar ranges (1-16 years). The distribution frequency of disease activity was similar in CD and UC groups. Most of the patients in both groups ( $58 \% \mathrm{CD}$ and $66 \% \mathrm{UC}$ ) displayed mild disease activity. Only 3 patients with UC (6\%) displayed severe disease activity, based on the Truelove-Witts score. The percent of patients treated with 


\begin{tabular}{|c|c|c|}
\hline \multicolumn{1}{|c|}{ Variable } & Crohn's disease & Ulcerative colitis \\
\hline Study population & $38(45 \%)$ & $47(55 \%)$ \\
\hline Age $(\mathrm{y})$ & $13(1-16)$ & $14(1-16)$ \\
\hline Sex & $16(42 \%)$ & $20(42 \%)$ \\
• female patients & $22(58 \%)$ & $27(58 \%)$ \\
• male patients & & \\
\hline Disease activity a,b & & $31(66 \%)$ \\
$\cdot$ mild & $22(58 \%)$ & $13(28 \%)$ \\
$\cdot$ moderate & $16(42 \%)$ & $3(6 \%)$ \\
• severe & $0(0 \%)$ & $11(23 \%)$ \\
Study groups & $16(42 \%)$ & $2(4 \%)$ \\
• azathioprine-treatedc & $1(3 \%)$ & $5(11 \%)$ \\
• adverse events & $7(18 \%)$ & \\
\hline • no response & & \\
\hline
\end{tabular}

All values represent the number (\%) of patients, except age, which is expressed as the median (range). aActivity index for Crohn's disease: mild:150-219; moderate:220-450; severe $>450$. ' $T$ The Truelove-Witts score was used to evaluate ulcerative colitis severity. ' $A$ zathioprine treatment was $2.5 \mathrm{mg} / \mathrm{kg} /$ day.

Table 1: Pediatric population demographics and disease characteristics.

\begin{tabular}{|l|l|l|l|}
\hline Therapeutic group & \multicolumn{2}{|l|}{ TPMT activity [U/mI RBC] } & $P$ \\
\cline { 2 - 3 } & Children & Adults & \\
\hline Crohn's disease & 13.12 & 13.67 & \\
& $(5.56-21.34)$ & $(9.61-17.84)$ & \\
& $\mathrm{n}=38$ & $\mathrm{n}=11$ & 0.415 \\
Ulcerative colitis & 13.19 & 13.15 & 0.607 \\
& $(4.74-22.56)$ & $(5.19-21.98)$ & \\
\hline & $\mathrm{n}=47$ & $\mathrm{n}=20$ & \\
\hline
\end{tabular}

Table 2: Thiopurine S-methyltransferase (TPMT) enzyme activity in pediatric and adult patients with inflammatory bowel disease. Values represent the median (range) of TMPT activity. Adults ages were (median [range] years): Crohn's disease: 19 (17-25), ulcerative colitis: 18 (17-23)

\begin{tabular}{|l|c|c|c|}
\hline \multirow{2}{*}{ Therapeutic group } & \multicolumn{2}{|l|}{ TPMT activity [U/mI RBC] } & \multirow{2}{*}{$\boldsymbol{P}$} \\
\cline { 2 - 3 } & Crohn's disease & Ulcerative colitis & \\
\hline AZA-treated & 12.96 & 12.89 & 0.921 \\
\hline Adverse events & $7.85-21.34$ & $4.74-22.56$ & 12.34 \\
\hline No response & 13.20 & 9.64 & $4.47-17.10$ \\
& - & $6.95-12.34$ & 0.667 \\
\hline & 13.20 & & 0.343 \\
\hline
\end{tabular}

\section{AZA: azathioprine}

Values represent medians and ranges of TPMT activity.

Table 3: Thiopurine S-methyltransferase (TPMT) enzyme activity in pediatric patients with inflammatory bowel disease.

azathioprine in the CD group was about twice that in the UC group, but the percentage of adverse events (myelosuppression, hepatotoxicity and pancreatitis) was similar between groups (i.e., 3-4\%). The median thiopurine S-methyltransferase (TPMT) activity in children was 13.12 $\mathrm{U} / \mathrm{ml} \mathrm{RBC}$ in $\mathrm{CD}$ and $13.19 \mathrm{U} / \mathrm{ml} \mathrm{RBC}$ in UC groups. The range of TPMT activity was not significantly different in children and adults with IBD (Table 2); 5.56-21.34 vs. 9.61-17.84 U/ml RBC, respectively, for $\mathrm{CD}$ and $4.74-22.56$ vs. 5.19-21.98 U/ml RBC, respectively, for UC. The distribution of TPMT activity in the whole study population (85 individuals) is graphically represented in Figure 2. TPMT activity levels showed a 4.8 -fold variability, ranging from 4.74 up to $22.56 \mathrm{U} /$ $\mathrm{ml} \mathrm{RBC}$. The TPMT activities in different pediatric therapeutic groups are presented in Table 3. The TPMT activity was similar between CD and UC groups for individuals treated with azathioprine, individuals that experienced adverse events, or individuals that failed to respond to azathioprine treatment. The latter two therapeutic response groups tended to have higher TPMT activities in the CD compared to the UC group, but the differences were not statistically significant.

Genotyping revealed that only one out of 85 patients $(1.18 \%)$ carried the G238C mutation; TPMT allele ${ }^{\star} 2$. That individual displayed a heterozygous genotype of $\mathrm{TPMT}^{*} 1 / \mathrm{TPMT}^{*} 2$, which was accompanied by a phenotype of low-intermediate TPMT activity $(5.19 \pm 0.05 \mathrm{U} / \mathrm{ml} \mathrm{RBC}$; measured in two independent venipuncture blood samples). Next, we genotyped individuals that displayed lowintermediate TPMT activity (i.e., $<8 \mathrm{U} / \mathrm{ml} \mathrm{RBC}$ ); these included two patients with activity $<5 \mathrm{U} / \mathrm{ml} \mathrm{RBC}$ and six patients with activity of 5-8 U/ml RBC. We screened these patient samples for the G460A and A719G mutations (TPMT alleles ${ }^{*} 3 A$, and ${ }^{*} 3 A^{\star} 3 C$, respectively). No $\mathrm{TPMT}^{\star} 3 A$ or $\mathrm{TPMT}^{\star} 3 \mathrm{C}$ polymorphisms were detected in this study group.

\section{Discussion}

Thiopurines including azathioprine are rapidly metabolized in competing pathways. One of these pathways is regulated by thiopurine S-methyltransferase (TPMT). Variation in TPMT activity is partly responsible for the variability of the clinical response to thiopurines, including adverse reactions. We investigated the impacts of inflammatory bowel disease (IBD) and age on TPMT activity. In our study group, a significant percentage of children with IBD (i.e., $32 \%$ ) had received azathioprine at some time during the course of the disease. This was consistent with other studies, which reported that 29$32 \%$ of children with IBD were treated with azatioprine $[13,14]$.

We found a significant male predilection for both CD and UC in children; both groups showed a male:female ratio of approximately 1.35 , in contrast adult IBD cohorts showed a mild female predominance [15]. The male predominance may suggest that the cohort was mainly sporadic [16], however, significant numbers of patients or their parents were unaware of family history, and therefore it was difficult to confirm

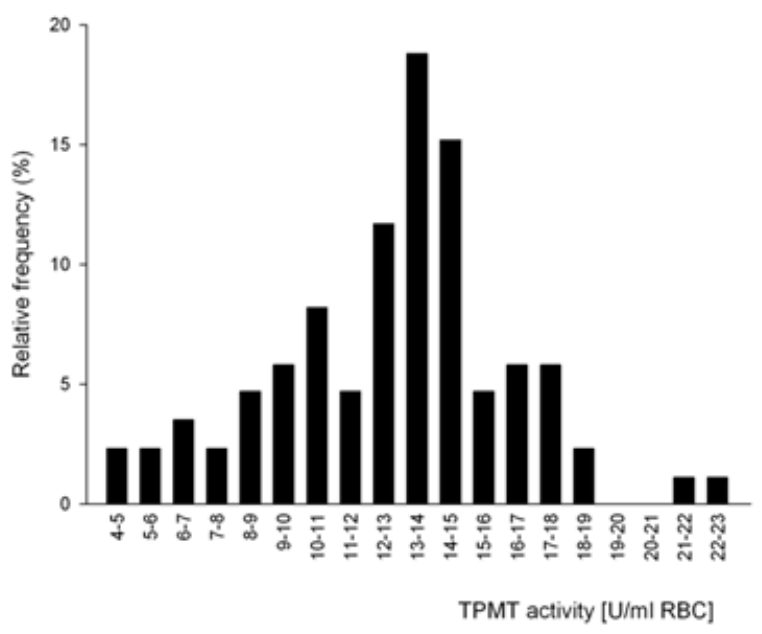

Figure 2: Frequency distribution histogram of thiopurine S-methyltransferase (TPMT) activity in children with inflammatory bowel disease. 
it. We provided evidence that TPMT activity was not significantly different between children with CD or UC. Furthermore, we showed that TPMT activity was not apparently altered in a relevant manner by age in CD and UC groups (Table 2). These results were consistent with data from large-scale cohort studies, which also showed that TPMT activity was not affected in a relevant manner by age [17]. However, some previous observations indicated that TPMT activity might change with age. For example, in a Norwegian population, higher TPMT activity was found in children than in adults [18]. Conversely, a different study detected a slightly lower TPMT activity in children compared to adults, but the difference appeared to be clinically irrelevant [19].

We also investigated whether low-intermediate TPMT activity may predispose patients to the occurrence of adverse drug reactions. In addition, we tested whether high enzyme activity might lead to no response. Interestingly, we did not observe significantly low TPMT activity levels in patients with CD and UC that had a history of adverse events after azathioprine. Moreover, a significantly high TPMT activity was not observed in the patients that exhibited no clinical response to azathioprine treatment. These data were accordance with clinical observations, where, although the percentage of patients treated with azathioprine was twice as high in the CD group as in the UC group, the percentage of adverse events was similar between groups i.e., 3-4\%. Moreover, it was previously suggested that TPMT activity may be increased with successive courses of azathioprine treatment, although the mean increase in TPMT activity was only $30-35 \%$ [20,21].

Our frequency distribution analysis of TPMT activity indicated a trimodal distribution. According to a previously published classification scale for TPMT activity [22], in our population, $9.41 \%$ displayed intermediate activity (3-8 U/ml RBC), 68.24\% displayed normal activity (8-15 U/ml RBC), and $22.35 \%$ displayed very high activity ( $>15 \mathrm{U} / \mathrm{ml} \mathrm{RBC}$ ). Our study population did not include any cases classified as low TPMT activity $(0-2.5 \mathrm{U} / \mathrm{ml} \mathrm{RBC})$. We used the clinical laboratory "cutoff" value of $15 \mathrm{U} / \mathrm{ml} \mathrm{RBC}$ to separate intermediate and high activity samples; this value is close to $13.7 \mathrm{U} /$ $\mathrm{ml} \mathrm{RBC}$, the nadir of the frequency distribution histogram for samples from healthy subjects [9]. We considered TPMT activities $<8 \mathrm{U} / \mathrm{ml}$ $\mathrm{RBC}$ to be low-intermediate values. Our cohort of children with IBD included a smaller percentage with low-intermediate TPMT activity 9.41\% than observed among healthy Europeans $-16.7 \%$, but similar to that observed among healthy Northern Americans - $11.7 \%[9,23]$.

Inter-individual variability in TPMT activity is partly caused by the presence of single nucleotide polymorphisms in the TPMT gene. Genotyping individuals for TPMT allele ${ }^{\star} 2$ revealed only one patient $(1.18 \%)$ that carried a heterozygous mutation of $\mathrm{TPMT}^{\star} 1 / \mathrm{TPMT}^{*} 2$. Moreover, this patient did not carry the TPMT $* 3 A$ or TPMT ${ }^{*} 3 \mathrm{C}$ alleles. The mutated genotype was accompanied by reduced TPMT activity. Further genetic analysis of patients with TPMT activity at the low end of the spectrum did not identify $\mathrm{TPMT}^{\star} 3 \mathrm{~A}$ or $\mathrm{TPMT}^{\star} 3 \mathrm{C}$ polymorphisms. The frequency of the TPMT ${ }^{*} 2$ allele in our population of children with IBD was similar to that found in adults from a European population i.e., $0.2-0.5 \%[24,25]$. Importantly, low-intermediate TPMT activity in children with IBD was mostly not associated with TPMT alleles $2 \mathrm{~A}$ , $3 A$, or $3 C$, which typically show the highest population penetration i.e., 60-95\%. This discordance between genotype and phenotype among individuals with wild-type genotype and deficient activity has been reported in previous studies [26].

In conclusion, the similar activity of thiopurine $S$-methyltransferase in children and adults with inflammatory bowel disease suggests that thiopurines may be metabolized in the similar swiftness in theses groups of patients.

\section{Acknowledgment}

This work was supported by grant no. NN407 340139 from the Polish Ministry of Science and Higher Education.

\section{References}

1. de Mesquita MB, Civitelli F, Levine A (2008) Epidemiology, genes and inflammatory bowel diseases in childhood. Dig Liver Dis 40: 3-11.

2. Ruemmele FM (2010) Pediatric inflammatory bowel diseases: coming of age Curr Opin Gastroenterol 26: 332-336.

3. Sahasranaman S, Howard D, Roy S (2008) Clinical pharmacology and pharmacogenetics of thiopurines. Eur J Clin Pharmacol 64: 753-767.

4. Duley JA, Florin TH (2005) Thiopurine therapies: problems, complexities, and progress with monitoring thioguanine nucleotides. Ther Drug Monit 27: 647654

5. Karas-Kuzelicki N, Mlinaric-Rascan I (2009) Individualization of thiopurine therapy: thiopurine S-methyltransferase and beyond. Pharmacogenomics 10: 1309-1322.

6. Szumlanski CL, Honchel R, Scott MC, Weinshilboum RM (1992) Human liver thiopurine methyltransferase pharmacogenetics: biochemical properties, livererythrocyte correlation and presence of isozymes. Pharmacogenetics 1: 148159

7. Weinshilboum RM, Sladek SL (1980) Mercaptopurine pharmacogenetics: monogenic inheritance of erythrocyte thiopurine methyltransferase activity. Am J Hum Genet 32: 651-662.

8. Garat A, Cauffiez C, Renault N, Lo-Guidice JM, Allorge D, et al. (2008) Characterisation of novel defective thiopurine S-methyltransferase allelic variants. Biochem Pharmacol 76: 404-415.

9. Otterness D, Szumlanski C, Lennard L, Klemetsdal B, Aarbakke J, et al. (1997) Human thiopurine methyltransferase pharmacogenetics: gene sequence polymorphisms. Clin Pharmacol Ther 62: 60-73.

10. Benkov K, Lu Y, Patel A, Rahhal R, Russell G, et al. (2013) Role of thiopurine metabolite testing and thiopurine methyltransferase determination in pediatric IBD. J Pediatr Gastroenterol Nutr 56: 333-340.

11. Weinshilboum RM, Raymond FA, Pazmiño PA (1978) Human erythrocyte thiopurine methyltransferase: radiochemical microassay and biochemical properties. Clin Chim Acta 85: 323-333.

12. Yates CR, Krynetski EY, Loennechen T, Fessing MY, Tai HL, et al. (1997) Molecular diagnosis of thiopurine S-methyltransferase deficiency: genetic basis for azathioprine and mercaptopurine intolerance. Ann Intern Med 126: 608-614.

13. Pozler O, Maly J, Bonova O, Dedek P, Frühauf $P$, et al. (2006) Incidence of Crohn disease in the Czech Republic in the years 1990 to 2001 and assessment of pediatric population with inflammatory bowel disease. J Pediatr Gastroenterol Nutr 42: 186-189.

14. Turunen $\mathrm{P}$, Kolho $\mathrm{KL}$, Auvinen $\mathrm{A}$, Iltanen $\mathrm{S}$, Huhtala $\mathrm{H}$, et al. (2006) Incidence of inflammatory bowel disease in Finnish children, 1987-2003. Inflamm Bowel Dis 12: 677-683.

15. Sauer CG, Kugathasan S (2009) Pediatric inflammatory bowel disease: highlighting pediatric differences in IBD. Gastroenterol Clin North Am 38: 611 628.

16. Peeters M, Cortot A, Vermeire S, Colombel JF (2000) Familial and sporadic inflammatory bowel disease: different entities? Inflamm Bowel Dis 6: 314-320.

17. Chouchana L, Narjoz C, Beaune P, Loriot MA, Roblin X (2012) Review article: the benefits of pharmacogenetics for improving thiopurine therapy in inflammatory bowel disease. Aliment Pharmacol Ther 35: 15-36.

18. Pettersson B, Almer S, Albertioni F, Söderhäll S, Peterson C (2002) Differences between children and adults in thiopurine methyltransferase activity and metabolite formation during thiopurine therapy: possible role of concomitant methotrexate. Ther Drug Monit 24: 351-358.

19. Ganiere-Monteil C, Medard Y, Lejus C, Bruneau B, Pineau A, et al. (2004) Phenotype and genotype for thiopurine methyltransferase activity in the French Caucasian population: impact of age. Eur J Clin Pharmacol 60: 89-96. 
Citation: Jankowski M,Landowski P,Kowalski R,Kreft E,Audzeyenka I, et al., (2013) Thiopurine S-Methyltransferase Phenotype and Genotype in Pediatric Patients with Inflammatory Bowel Disease; Implication for Azathioprine Treatment. J Pharmacovigilance 1: 113. doi:10.4172/2329-6887.1000113

Page 5 of 5

20. Keuzenkamp-Jansen CW, Leegwater PA, De Abreu RA, Lambooy MA, Bokkerink JP, et al. (1996) Thiopurine methyltransferase: a review and a clinical pilot study. J Chromatogr B Biomed Appl 678: 15-22.

21. Lennard L, Lilleyman JS, Van Loon J, Weinshilboum RM (1990) Genetic variation in response to 6 -mercaptopurine for childhood acute lymphoblastic leukaemia. Lancet 336: 225-229.

22. Ansari A, Hassan C, Duley J, Marinaki A, Shobowale-Bakre EM, et al. (2002) Thiopurine methyltransferase activity and the use of azathioprine in inflammatory bowel disease. Aliment Pharmacol Ther 16: 1743-1750.

23. Spire-Vayron de la Moureyre C, Debuysere H, Mastain B, Vinner E, Marez D, et al. (1998) Genotypic and phenotypic analysis of the polymorphic thiopurine S-methyltransferase gene (TPMT) in a European population. Br J Pharmacol 125: 879-887.
24. Schaeffeler E, Fischer C, Brockmeier D, Wernet D, Moerike K, et al. (2004) Comprehensive analysis of thiopurine S-methyltransferase phenotypegenotype correlation in a large population of German-Caucasians and identification of novel TPMT variants. Pharmacogenetics 14: 407-417.

25. Booth RA, Ansari MT, Loit E, Tricco AC, Weeks L, et al. (2011) Assessment of thiopurine S-methyltransferase activity in patients prescribed thiopurines: a systematic review. Ann Intern Med 154: 814-823, W-295-8.

26. Donnan JR, Ungar WJ, Mathews M, Rahman P (2011) Systematic review of thiopurine methyltransferase genotype and enzymatic testing strategies. Ther Drug Monit 33: 192-199.
This article was originally published in a special issue, Pharmacovigilance and Pharmacogenetics handled by Editor(s). Dr. Tibebe Woldermariam, Department of Medicinal Chemistry California Northstate University, United States 